\title{
Development of Mini Wind Turbine Generator
}

\author{
Sahazati Md Rozali, Rozilawati Mohd Nor, Muhammad Nizam Kamarudin, Mohd Shahrieel \\ Mohd Aras
}

\begin{abstract}
Most of the electricity generation process in Malaysia using fuel sources especially coal and natural gasses. The country needs to spend higher cost to import this source since it is not a natural resource in Malaysia. In addition, the usage of coal as resources affected the environment. The extinction of this source also needs to be considered since it is not a renewable energy sources. Therefore, a prototype of mini wind turbine generator is proposed in this research in order to study the effectiveness of this type of generator since it is one of the alternatives to generate electricity. It is developed in Archimedes design by using microcontroller. The performance is evaluated by analyzing the blade material, number of blades and the environment influence on the location of wind turbine generator. The results show that the blade made from acrylic with lowest number of blades produced higher voltage and current while the location of the designed prototype at high hill area generate higher value of voltage and current compared to the beach and field area.
\end{abstract}

Keywords: wind turbine, blade material, number of blade, system's location..

\section{INTRODUCTION}

In a developing country, energy is considered as one of the driving force for its socio-economic [1]. Based on the information by International Energy Efficiency, in 2014 and 2015 , fossil fuels burning generate about $80 \%$ of the world primary energy. This situation increased global greenhouse gas (GHG) emission dramatically [2]. In addition, the world GHG emission from fossil fuel combustion is expected to increase from $54 \mathrm{Gt} \mathrm{CO} 2$-eq in 2010 to $70 \mathrm{Gt} \mathrm{CO} 2$-eq in 2050 [3]. Therefore, renewable and environmentally friendly energy resources such as hydro and wind energy become the new target of many countries in the world and they are moving towards it. The hydropower is a clean, renewable, and cheap source of electricity [4]-[6].

Electricity is one of the important energy in daily use. It comes from various sources throughout the world. There are renewable as well as non-renewable energy sources. This energy can be generated from solar panel, wind turbine, nuclear, petroleum, natural gas, geothermal resources and etc. In Malaysia, most of electricity is generated by using fuel sources such as coal and natural gas.

Since coal is not a natural resource in Malaysia, the country needs to spend higher cost to import this source.

Revised Manuscript Received on September 14, 2019.

Sahazati Md Rozali*, Center for Robotics and Industrial Automation (CeRia), Department of Electrical Engineering Technology, Faculty of Electrical and Electronic Engineering Technology, Universiti Teknikal Malaysia Melaka, Malaysia. (Email: sahazati@utem.edu.my)

Rozilawati Mohd Nor, Dept of Electrical Engineering Technology, Faculty of Electrical and Electronic Engineering Technology, Universiti Teknikal Malaysia Melaka, Malaysia. (Email: rozilawati@utem.edu.my)

Muhammad Nizam Kamarudin, Faculty of Electrical Engineering, Universiti Teknikal Malaysia Melaka, Malaysia. (Email: nizamkamarudin@utem.edu.my)

Mohd Shahrieel Mohd Aras, Faculty of Electrical Engineering, Universiti Teknikal Malaysia Melaka, Malaysia. (Email: nizamkamarudin@utem.edu.my, shahrieel@utem.edu.my.)
This situation contributes as one of the major expenditure of the country. The usage of coal as resources also affects the environment. In addition, the extinction of this electricity source is also the issue that needs to be addressed today. Therefore, a study on the effectiveness of mini wind turbine generator is proposed in this research in order to overcome this problem. The prototype of this generator is suggested to be developed since it is a natural and renewable source.

\section{WIND TURBINE SYSTEM}

The thought of harnessing wind flow energy to create mechanical power goes back for millennia. During 5000 B.C., Egyptians used wind flow energy to propel boats along the Nile River while American colonists relied on wind turbines to grind grain, pump normal water and cut wood at sawmills. Today, wind turbines are used in contemporary and commercially method. It is a device that converts the kinetic energy in wind into clean electricity. The operation of this system starts when the wind spins the turbine's blades. A rotor captures the kinetic energy of the wind and converts it into rotary motion to drive the generator. The generator converts this power into electricity so that it may be used for the benefit of mankind. Since wind is a natural occurrence, unlimited, free and renewable source, it is one of the best alternatives to harvest a clean wind power and non-polluting way to generate electricity. Unlike other types of power plants, it emits no air pollutants or greenhouse gasses. Wind energy is eco-friendlier than the burning of fossil fuels for electricity.

The main components of wind energy system are rotor and its blades, shaft and electric generator. Wind turbines work by converting the kinetic energy from the wind into rotational energy in the turbine. The rotational energy is then converted into electrical energy. The energy conversion depends on the wind speed and the swept area of the turbine. Fig. 1 shows the swept area that is the region where the turbine can capture the kinetic energy [7]. 


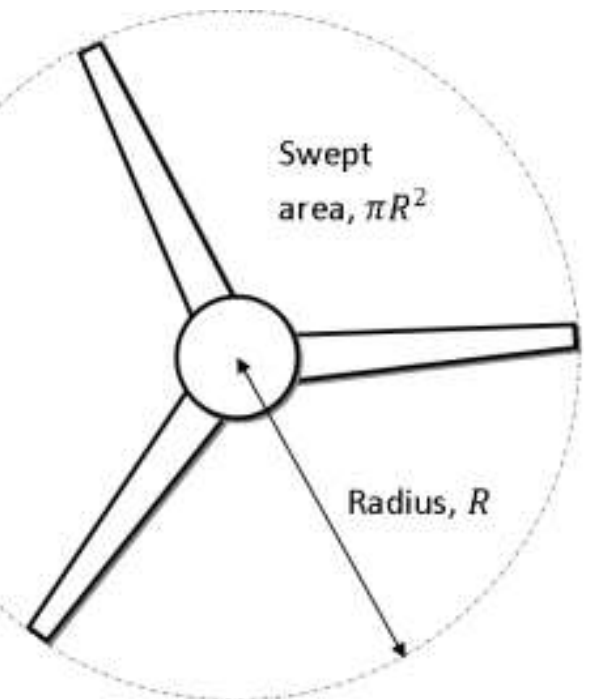

Fig.1.Turbine swept area.

Rotor blade design is one of the main part of wind turbine system. The design of this part has benefited from airplanes wind technology. The shape of the rotor blade and its angle of attack relative to the wind direction affects its performance. In addition, its material which are usually made of wood solid or laminated, fiberglass or metal and number of blade also affect its action.

Usually, wind generators contain three blades set up in a tower produced from tubular steel. Some of them is developed with two blades by using concrete or metal lattice towers. With 100 feet or higher above the bottom, the tower allows the turbine to produce more electrical supply by taking advantage of faster wind speeds at higher altitudes. The turbines operate by catching the wind's energy utilizing their propeller-like blades, which actions very much as an aircraft wing and this energy will be converted to electrical energy by its operating system.

There are several advantages of two-blades compared to three-blade wind turbine system. One of them is it has lighter weight. Therefore, it is easier to handle and assemble the system. In addition, it also reduces the cost since using fewer blades allows designers to use lighter components such as low-speed shaft, mainframes, and tower. Besides, fewer blades yield fewer noise production surfaces. Noise is one of the issues that must be considered when constructing wind turbine. This research focused on producing electricity energy by using wind turbine system and the performance of the designed system will be analysed based on different number and rotation speed of blades.

Wind turbine is categorized into two categories. They are horizontal and vertical axis wind turbine. The smallest wind turbine will produce less than $10 \mathrm{~kW}$ by using permanent magnet generator. The size allows it to be used for general application and mounted almost everywhere. A number of gears improve the rotation of the rotor from about $18 \mathrm{rpm}$ to roughly $1,800 \mathrm{rpm}$ and allows the turbine's generator to produce electricity.

Fig. 2 illustrates the basic diagram of horizontal-axis wind turbines (HAWT). It consists of primary rotor shaft and power generator. The power generator is located near the top of a tower. Thus, it could be pointed into or from the wind. Based on the figure, small turbine is pointed by a straightforward wind vane, while a wind sensor in conjunction with a servo motor is used in large turbine. Then, the gearbox turns the rotation of the blades to a suitable rotation in order to operate an electrical generator.

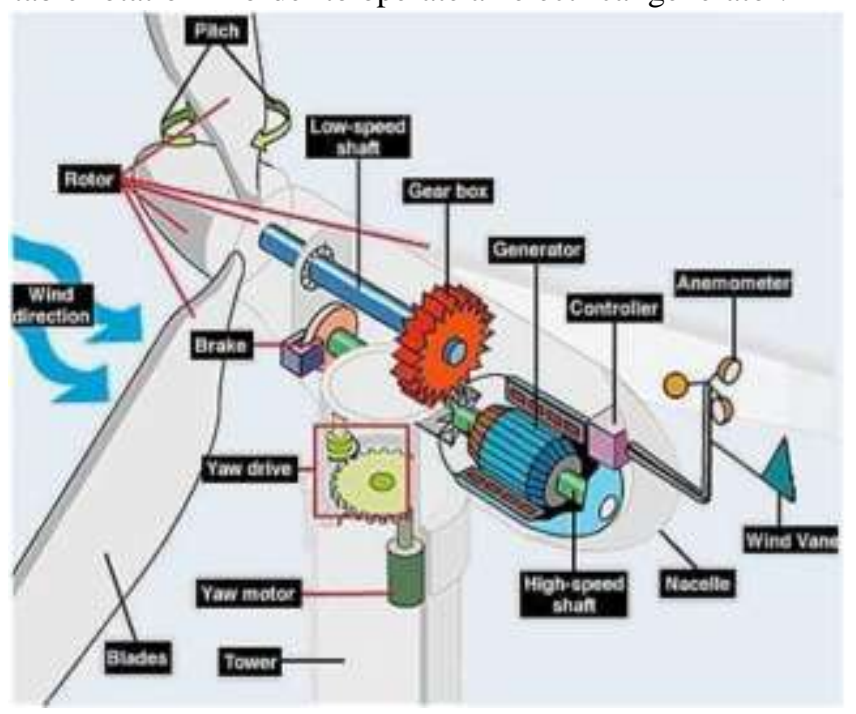

Fig. 2.Design of HAWT.

Referring to Fig. 2, the lifting style wind generator blade is used since this designed is specifically for capturing energy of solid and fast wind. The aerodynamic form of rotor is created in order to arrest the wind surface such that it can spin ergonomically. The blades are light-weight, corrosion-resistant and durable material. The best component for blades is combination of fiberglass and protected plastic material. A gear box enlarges the energy produced by rotor. It is located between rotor and generator. The generator is being rotated by a rotor. It produces electricity from the spinning of the rotor. Generators can be found in different sizes. The nacelle may be the casing that covers and defends the apparatus and generator box from the elements. The tail vane guides the turbine to assemble highest wind energy.

On the other hand, the vertical axis wind turbine has turbine blade styles possibly vertical. The vertical axis wind mill blades are mounted on a central vertical shaft. This is one of the advantages of this type of turbine compared to the horizontal wind turbine styles. It is also unidirectional and will not require any unique yaw mechanisms to continually orient itself toward the wind path. In addition, its vertical travel shaft simplifies installing the gearbox and the power generator on the floor, making the framework and maintenance easier. Although there is a huge selection of commercial available vertical axis wind turbine design, horizontal axis wind turbine is preferred to use compared to vertical axis wind turbine. One of the reason is the vertical axis wind turbine is not suitable to be installed in a high tower. Fig. 3 shows the example of vertical axis wind turbine. 


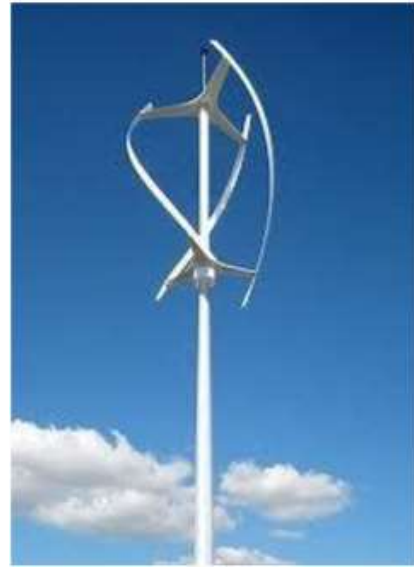

Fig. 3.Example VAWT.

In [8] develop the low cost wind generator that has the ability to supply electricity to particular household and at the same time it can be linked to the power grid such that the excess power can be sold to utility company. A PICcontrolled DC/DC boost converter is designed by [9] in order to track the utmost power point. The research shows that the designed converter is operate in $35 \%$ higher than the standard mode converter. In addition, it is easily adapted to various wind turbine models. In [10] create an isolated small wind turbine emulator with a separate DC motor and measure the performance of the system using different control strategies. The controller uses the wind rate and rotor speed parameter to control the operation of the buckincrease converter such that the wind turbine works at the ideal tip-speed ratio. Test results indicate that the proposed system emulates the behavior of a mini wind turbine system accurately. In [11] develop a prototype of a small battery charger by using PIC 16F877A microcontroller, liquidcrystal screen (LCD), silicon controlled rectifier (SCR), rectifier diodes and various other electronic components. The designed prototype has the ability to charge current up to 7A. in [12] design Archimedes spiral type wind turbine in a small scale based on Archimedean spiral concepts. This type of wind turbine harvests energy from the wind by redirecting its movement 90 degrees in accordance with the original path. Unlike traditional horizontal wind axis turbine system which involve lift push in order to extract power from wind energy, the Archimedes spiral wind turbine uses both drag and lift force for similar objective.

\section{METHODOLOGY}

Design selection is the important aspect that needs to be considered in order to develop a good wind turbine. The main objective in a wind turbine design is to ensure the maximum aerodynamic efficiency or energy is extracted from the wind. However, this goal must be met with the suitable mechanical strength criteria and low cost because number of blades in the wind turbine increases the aerodynamic efficiency but in a diminished way. When the number of blades is increased from 2 to 3 , the efficiency gains are smaller. The increment number of blades is proportional with the cost. With a larger number of blades, the blade should be thinner to be aerodynamic efficiently. On the other hand, the blade with thin part of the roots may not be able to withstand the bending pressure caused by axial wind loads. Hence, generally a wind turbine with 3 blades can accommodate thick cross-section of thickness is used. In this project, the Archimedes design will be used for analysis. Fig. 4 illustrates the isometric view of Archimedes design of wind turbine.

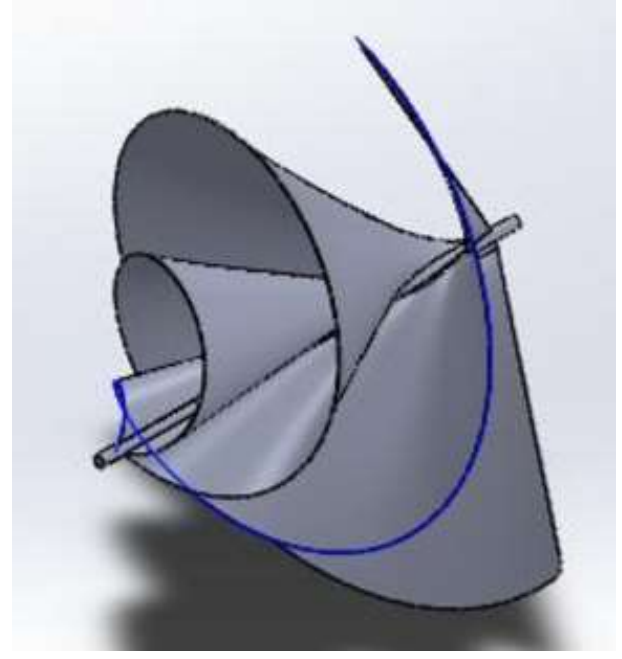

Fig. 4: The isometric view of Archimedes design of wind turbine

This design is chosen because it has the ability to harvest wind energy by redirecting its flow 90 degrees relative to the original direction. The traditional horizontal wind turbine system uses lift force to generate power while Archimedes spiral wind turbine uses both lift and drag force for the same purpose. Thus, it has the capability to utilize more kinetic energy and can be operated at lower speed. The prototype of mini wind turbine system is developed by using 3V-24V mini 3-phase generator, liquid crystal display (LCD), infrared (IR) sensor, Arduino as a controller and PVC pipe as a holder. The block diagram of the mini wind turbine is shown in Fig. 5.

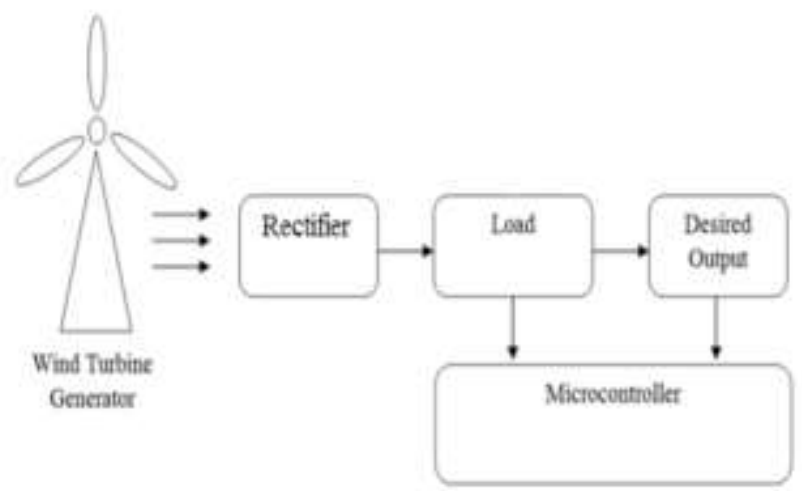

Fig. 5.Block diagram of mini wind turbine system.

The Archimedes blade is modelled by using Solid Work. The detail of the designed model is list down in Table I. 


\section{DEVELOPMENT OF MINI WIND TURBINE GENERATOR}

Table- I: Parameter of blades

\begin{tabular}{|l|l|}
\hline Parameter & $\begin{array}{l}\text { Dimension } \\
(\mathrm{mm})\end{array}$ \\
\hline Blade thickness & 2.0 \\
\hline $\begin{array}{l}\text { Radius of the } \\
\text { blade }\end{array}$ & 150 \\
\hline $\begin{array}{l}\text { Height of the } \\
\text { model }\end{array}$ & 300 \\
\hline $\begin{array}{l}\text { Length of the } \\
\text { model }\end{array}$ & 270 \\
\hline $\begin{array}{l}\text { Width of the } \\
\text { model }\end{array}$ & 300 \\
\hline
\end{tabular}

The electrical part is designed by using Proteus. The body or the holder of this prototype is shown in Fig. 6. It is created by using PVC.

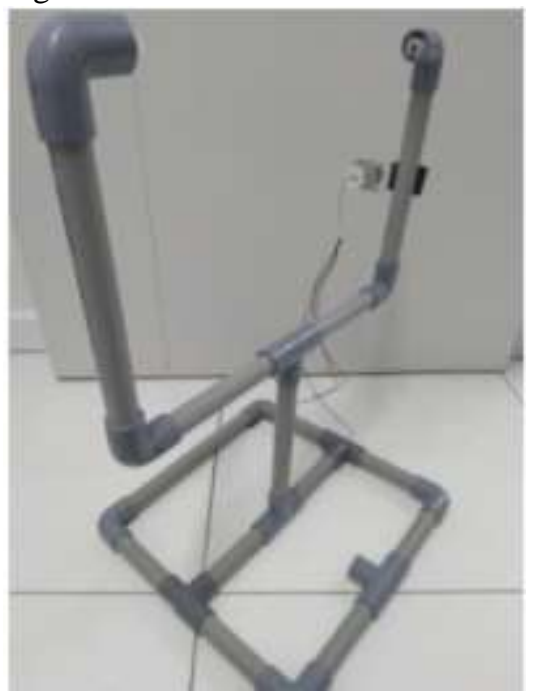

Fig. 6.Body of mini wind turbine system.

The Arduino circuit and LCD are also connected to this system. The Arduino circuit and LCD are illustrated in Fig. 7 and 8 respectively.

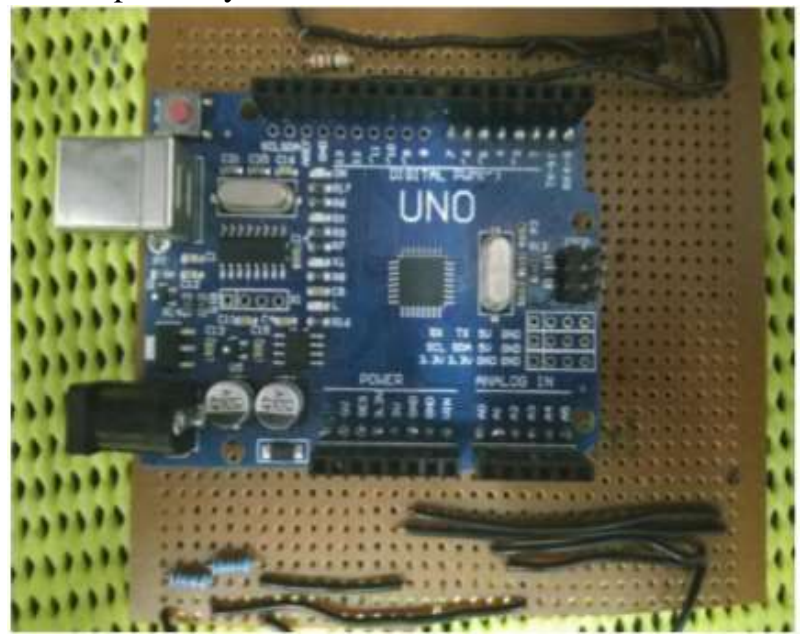

Fig. 7.The Arduino circuit connected to mini wind turbine system.

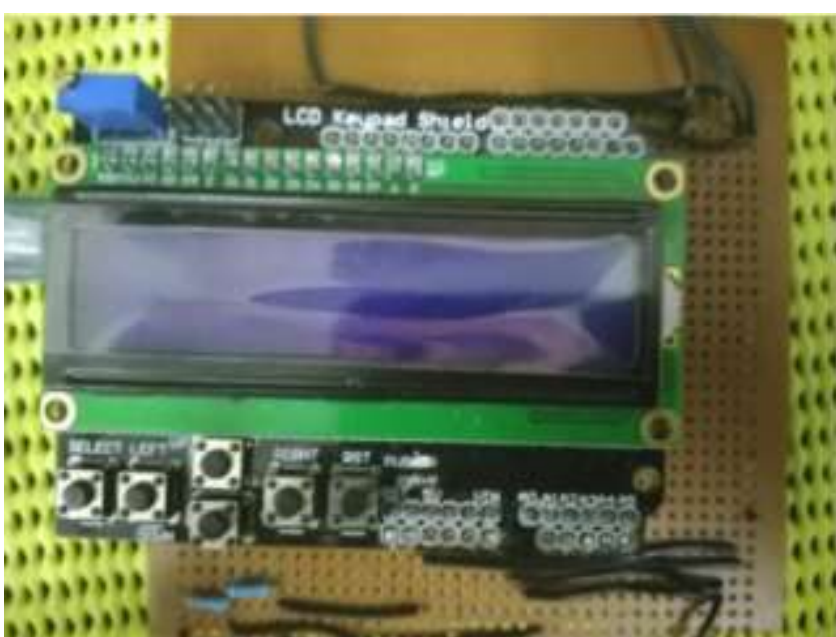

Fig. 8. The LCD circuit.

The complete prototype of mini wind turbine system is illustrated in Fig. 9. Archimedes blade, IR sensor, Arduino controller, LCD and PVC holder are combined together in the complete model.

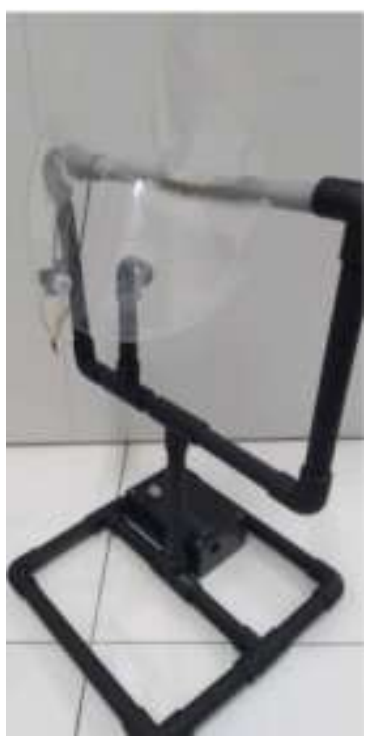

Fig. 9.Prototype of mini wind turbine system.

\section{RESULTS AND DISCUSSION}

The effectiveness and performance of the designed system is analyzed based on different blades' material, blades' number and the location of the system. Three different material are used in order to create the blades of the wind turbine system; zinc, alloy and acrylic. Zinc is chosen because of its durability and corrosion resistance while alloy is selected since its characteristics are lightweight, corrosion resistance, reflectivity and ductility. Since acrylic is easy to fabricate, it is also chosen to been used for blades creation. Besides, though acrylic is lighter, it has strong structure and highly transparent. Fig. 10 illustrates the voltage and current produced by using different material of blades.

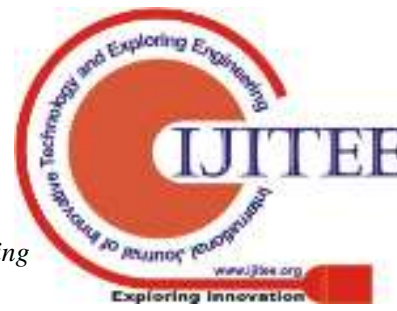




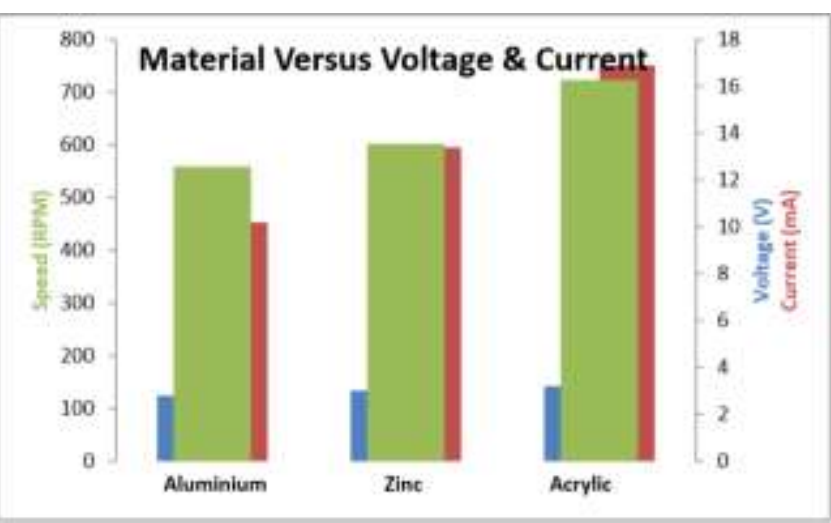

Fig. 10.The voltage and current produced by using different type of blade's material.

Based on the above figure, acrylic blades produced higher voltage and current compared to the other two. In addition to this analysis, the designed prototype is located in three different locations; field area, beach area and higher area. The voltage and current produced in these three different locations are measured and it is represented by Fig. 11. The graph shows that higher area produced higher value of voltage and current compared to the other two locations.

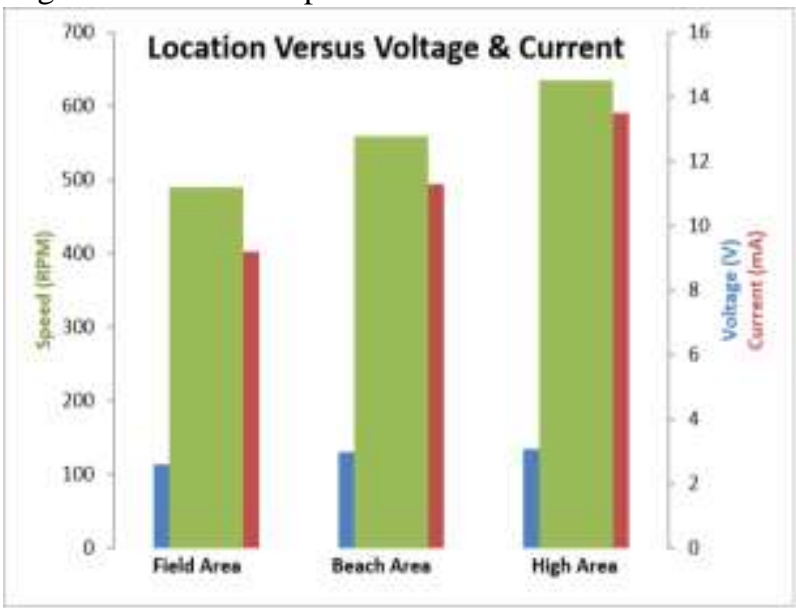

Fig. 11.The voltage and current produced in three different locations.

Another analysis is implemented to observe the effect of different number of blades on the voltage and current production by this mini wind turbine system. This analysis Fig. 12-14 show the voltage and current produced by using these number of blades respectively.

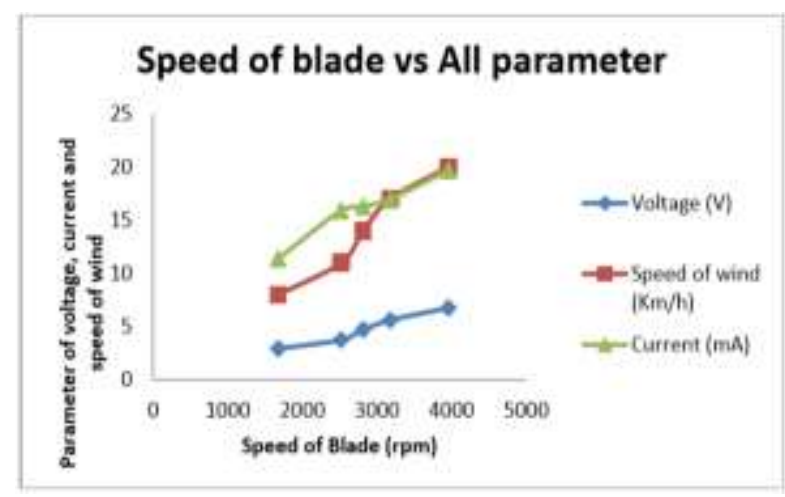

Fig. 12.Blade speed versus all current and voltage produced by using 2-blades. is completed by construct the system with 2, 3 and 4 blades.

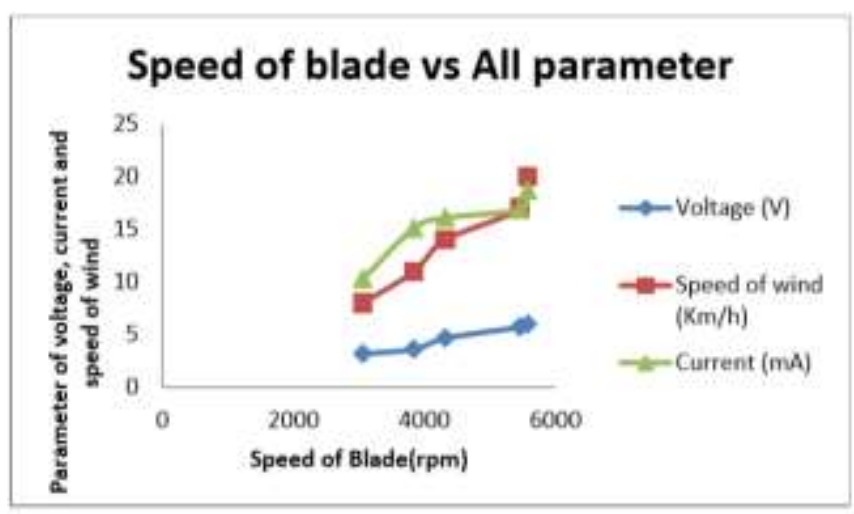

Fig. 13.Blade speed versus all current and voltage produced by using 3-blades.

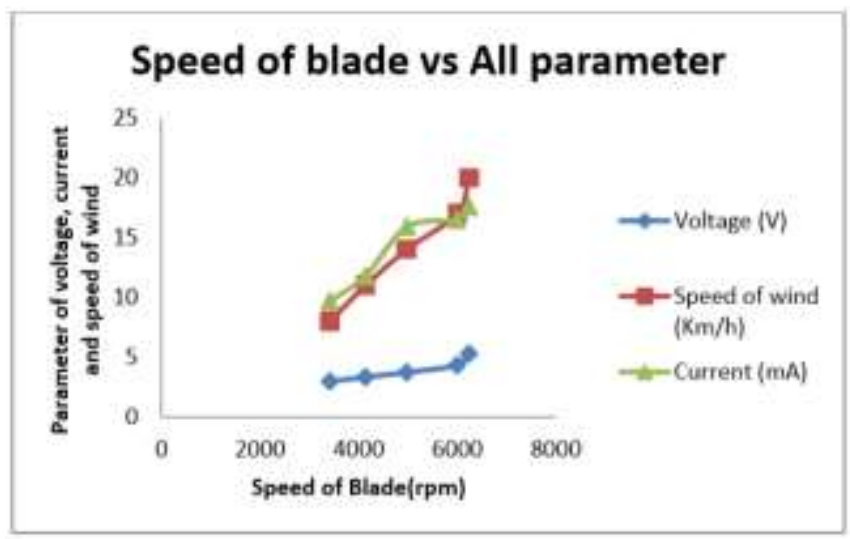

Fig. 14.Blade speed versus all current and voltage produced by using 4-blades.

Referring to the graph obtained in Fig. 10-12, higher voltage and current is produced when the rotation speed is increased. The speed increment yields faster blade rotation such that higher voltage and current is generated. Besides, based on these three plots, within certain range of rotation speed, 2-blades produced higher voltage and current compared to 3-blades and 4-blades. This might happen because less number of blades is lighter than higher number of blades such that the rotation is easier.

\section{CONCLUSION}

A prototype of mini wind turbine system is developed in this research as a simple benchmark to study the effectiveness of higher design of this system later. Based on the operation of this prototype of the system, blades' material, rotation speed and number of blades affect the performance of the designed system. Acrylic blade with lower number of blades and the location of the designed system at windy environment produced higher electricity energy.

\section{ACKNOWLEDGMENT}

This project is the pre-requisite to the grading of the course in the Bachelor of Electrical Engineering Technology (Industrial Power) [BETI] in the Faculty of Electrical and Electronic Engineering Technology in UTeM. Special

Published By: 
appreciation to FRGS grant numbered FRGS/2018/FTKEECERIA/E00382 for supporting this project.

\section{REFERENCES}

1. A. S. N. Huda, S. Mekhilef, and A. Ahsan, "Biomass energy in Bangladesh: Current status and prospects," Renewable and Sustainable Energy Reviews, 30, 2014, pp. 504-517.

2. M. Hossain, S. Mekhilef, M. Danesh, L. Olatomiwa, and S. Shamshirband, "Application of extreme learning machine for short term output power forecasting of three grid connected PV systems," Journal of Cleaner Production, 167, 2017, pp. 395405.

3. M. S. Uddin and S. Kumar, "Energy, emissions and environmental impact analysis of wind turbine using life cycle assessment technique," Journal of Cleaner Production, 69, 2015, pp. 153-164.

4. N. A. Iliadis and E. Gnansounou, "Development of the methodology for the evaluation of a hydropumped storage power plant: Swiss case study," Energy Strategy Reviews, 9, 2016, pp. 8-17.

5. M. A. H. Mondal, M. Denich, and T. Mezher, "Deployment of renewable energy technologies in Bangladesh: Long-term policy implications in power sector," Energy Strategy Reviews, 2, 2014, pp, 307-312.

6. G. N. P. de Moura, L. F. L. Legey, G. P. Balderrama, and M. Howells, "South America power integration, Bolivian electricity export potential and bargaining power: An OSeMOSYS SAMBA approach," Energy Strategy Reviews, 17, 2017, pp. 27-36.

7. M. N. Kamarudin, A. R. Husain, M. N. Ahmad, and Z. Mohamed, "Model and analysis of wind speed profile using artificial neural network - Feasibility study in Peninsular Malaysia," Jurnal Teknologi, 74(1), 2015, pp. 77-81.

8. R. Muhida, A. F. A. Zaidi, A. Tamsir, and R. Irawan, "Design of a DC-AC link converter for $500 \mathrm{~W}$ residential wind generator," Mechatronics, Electrical Power, and Vehicular Technology, 3(2), 2012, pp. 95-102.

9. E. Koutroulis and K. Kalaitzakis, "Design of a maximum power tracking system for wind-energy conversion applications," IEEE Transactions on Industrial Electronics, 53(2), 2006, pp. 486-494.

10. M. Arifujjaman, M. T. Iqbal, and J. E. Quaicoe, “An isolated small wind turbine emulator," Canadian Conference on Electrical and Computer Engineering, 2006, pp. 1854-1857.

11. A. S. Myint, H. M. Tun, and Z. M. Naing, "Implementation of wind turbine controller design for smart campus," International Journal of Scientific and Research Publications, 4(5), 2014, pp. $1-10$.

12. R. K. Kanakaraddi, R. P. Shivaraj, and C. Hooli, "Design and analysis of archimedes wind turbine," International Journal for Research in Applied Science and Engineering Technology, 5, 2017, pp. 2321-9653

\section{AUTHORS PROFILE}

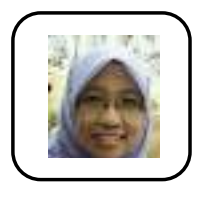

Sahazati Md Rozali was born in Melaka on $19^{\text {th }}$

February 1981.She received her degree in Bachelor of Electrical \& Electronic Engineering (Electronic) in 2004 from Universiti Sains Malaysia. Then she pursued her Master in Electrical Engineering (Control, Automation \& Robotics) in Universiti Teknologi Malaysia on 2006 and Doctor of Philosophy in Electrical Engineering from the same university in 2014. She is a member of Board of Engineers Malaysia (BEM) and Malaysian Board of Technologist (MBOT). Her specialization is in control system, modelling and system identification.

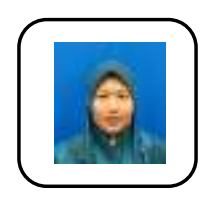

Rozilawati Mohd Nor is born in Miri, Sarawak on $27^{\text {th }}$ May 1988. She finished her first degree in Bachelor of Electrical Engineering (Control, Instrumentation \& Automation) on 2011 then completed her Master of Science in Electrical Engineering on 2015 at Universiti Teknikal Malaysia Melaka. Now she is lecturer at Faculty of Electrical and Electronic Engineering Technology, Universiti Teknikal Malaysia Melaka. Her major field of study is in control system and most of her publications are in control system design and application. She is a member of Board of Engineers Malaysia (BEM) and Malaysian Board of Technologist (MBOT)

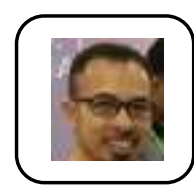

Muhammad Nizam Kamarudin was born in Selangor, Malaysia. He received the B.Eng (Hons.) Electrical from the Universiti Teknologi MARA, Malaysian in 2002, and M.Sc in Automation and Control from the University of Newcastle Upon Tyne, United Kingdom in 2007. He received the Doctor of Philosophy in Electrical Engineering from the Universiti Teknologi Malaysia in 2015. He is currently with the Universit Teknikal Malaysia Melaka (UTeM). He is the member of the Board of Engineers, Malaysia and Institute of Engineers, Malaysia.

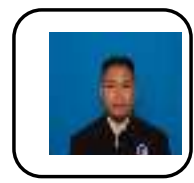

Dr. Mohd Shahrieel Mohd Aras is Associate Professor at Faculty of Electrical Engineering, Universiti Teknikal Malaysia Melaka UTeM. His current research is focusing on control system design of underwater technology. His primary interests related to underwater robotics and Artificial Intelligence. 